\title{
Gênese e transformações socioespaciais em um bairro periférico: o caso da Vila Odilon na cidade de Ourinhos-SP
}

\author{
Socio-space formation in a peripheral neighborhood: the case of Vila Odilon \\ in the city of Ourinhos-SP
}

Franciele Ferreira Dias ${ }^{A}$
${ }^{a}$ Professora substituta na Universidade Federal da Integração Latino-Americana (Unila), doutora em Geografia pela Universidade Estadual de Londrina (UEL).
E-mail: franciele.ferreiradias@gmail.com

\begin{abstract}
A ferrovia e o café contribuíram para a criação, ainda na década de 1910, de vários núcleos urbanos no interior paulista, a cidade de Ourinhos sendo um deles. Concomitantemente, surge um povoado cuja proximidade com o rio Paranapanema contribuiu para a criação de olarias, que o transformando no primeiro bairro periférico: a Vila Odilon. Esse bairro e sua atividade fabril foram o início da industrialização de Ourinhos, uma vez que a atividade econômica foi propulsora do desenvolvimento e da expansão urbana da Região Sul da cidade. O trabalho de campo no local estudado, a coleta de informações e o estudo da literatura sobre a história de Ourinhos possibilitaram construir este trabalho. Expõem-se, nesta pesquisa, as transformações socioespaciais que a Vila Odilon - outrora periférica - passou durante o processo de valorização imobiliária, mesmo com a quebra de parcela das olarias ocorrida a partir da década de 1990. Entretanto, tal vila conserva elementos que constituem sua singularidade, dentre eles a grande quantidade de olarias em atividade e desativadas, motivo pelo qual ainda é conhecida como o "bairros das olarias".
\end{abstract}

Palavras-chave: Ourinhos, espaço urbano, olarias.

\begin{abstract}
The railroad expansion and the coffee industry contributed to the creation, still in the 1910's, of several urban centers in the countryside of São Paulo, such as Ourinhos. At the same time, a village emerged in proximity to the Paranapanema River, which contributed to the creation of potteries, transforming it into the first peripheral district: Vila Odilon. This neighborhood and its industrial activity pioneered the industrialization in Ourinhos, since this economic activity was the driving force behind the urban development and expansion of the city's southern region. Based on field research, data collection, and literature search on the history of Ourinhos, we investigated the socio-spatial transformations that Vila Odilon - once peripheral - underwent in process of real estate valorization, even with the shutdown of the potteries from the 1990s onwards. However, Vila Odilon still preserves elements that constitute its singularity, such as the large number of potteries (active and deactivated), being known as the "neighborhood of the potteries".
\end{abstract}

Keywords: Ourinhos, urban space, pottery activity. 


\section{INTRODUÇÃO}

O objetivo deste trabalho é discutir os processos de gênese e as transformações socioespaciais na Vila Odilon, localizada em Ourinhos, São Paulo. A gênese da cidade se relaciona com o cultivo de café e a instalação dos trilhos da ferrovia Sorocabana. No caso da Vila Odilon, adiciona-se a relação entre o rio Paranapanema e a atividade das olarias, quanto à produção de telhas e tijolos. Essa atividade foi muito importante para a economia municipal até meados da década de 1990 e para a ocupação e desenvolvimento da Vila Odilon e da região $\mathrm{Sul}^{1}$ da cidade.

A Vila Odilon é o bairro mais antigo e central de sua região, atualmente composta pelos loteamentos/ vilas Vila São José, Vila Musa, Vila Adélia e Vila São Francisco, oriundos da expansão das olarias e do processo de urbanização dela resultante. Popularmente, a região das olarias é separada pela Vila Odilon e Vila Musa, já nas proximidades da rodovia Mello Peixoto, embora existam algumas localizadas na Cohab Padre Eduardo Murante, que foram criadas em um período anterior ao bairro em si. As transformações estão associadas à decadência do setor oleiro a partir da década de 1990 e ao desenvolvimento do eixo comercial e de serviços na avenida Domingos Camerlingo Caló, alterando o caráter fabril do bairro, embora uma parcela da atividade oleira ainda resista. Outros processos são a valorização imobiliária após a década de 2000 e a expansão urbana.

O estudo da Vila Odilon justifica-se pois: 1) trata-se do bairro periférico mais antigo de Ourinhos; 2) as olarias foram importantes para a ocupação da região Sul da cidade e para a economia municipal; 3) o processo de valorização imobiliária, a decadência da atividade oleira e a criação de eixo comercial e de serviços levou ao processo de reprodução do espaço urbano.

Este trabalho é parte da pesquisa realizada pela autora durante o mestrado em Geografia, sendo revisitado quanto à atualização de informações, conceitos e coleta de dados, mediante trabalho de campo em junho de 2021. Foram utilizados autores que abordavam a história da cidade e foi consultado o Plano Diretor de Ourinhos de 2018. Realizaram-se entrevistas com os senhores Amílcar João Moretti, morador há 57 anos da Vila Odilon, sobre aspectos do cotidiano do bairro, e com Eitor Martins, proprietário da imobiliária Shalom, sobre a valorização imobiliária de 2011. Em 2021 realizou-se entrevista com o senhor Sidney, morador da Vila Odilon e trabalhador da olaria Ourily, acerca da atual situação do setor.

\section{A GÊNeSe De OuRInHos E DA VILA ODILON}

A gênese de Ourinhos se relaciona em parte com a frente pioneira (MONBEIG, 1984) e com a ampliação dos cafeeiros em direção ao centro-oeste paulista e ao norte pioneiro paranaense. Além disso, a expansão da ferrovia Sorocabana serviu inicialmente como elemento conector entre as cidades, funcionando como meio de transporte, escoamento da produção de café e difusão de informações. Conforme Del Rios (1992), ocorreu, em 1905, a gênese de Ourinhos. A ocupação se iniciou devido à influência do pioneiro Jacinto Ferreira de Sá, que já possuía 1.065 alqueires de terras em Ourinhos e que adquiriu, no início de 1908, mais 1.230 alqueires, somando quase a totalidade da área urbana atual do município. A partir disso ocorreu a inauguração da Estação Ferroviária da Sorocabana no município, em 1908.

O núcleo urbano inicial desenvolveu-se ao norte da Estação Ferroviária Sorocabana, denominado como "abaixo da linha". A linha férrea era um divisor de classes sociais até a década de 1950, pois dividia a cidade em um lado desenvolvido social e economicamente, denominado "acima da linha", e outro menos desenvolvido, o lado "abaixo da linha". Junto ao pátio de manobras da ferrovia havia uma vila habitada pelos ferroviários. $\mathrm{Na}$ figura 1 se observam os locais descritos.

1 A região Sul de Ourinhos é composta pelos bairros Cohab Padre Eduardo Murante, Jardim Itamaraty, Jardim Matilde, Jardim Pacheco Chaves, Vila Musa, Vila São Silvestre e Vila Odilon (PREFEITURA DE OURINHOS, 2018).

2 Este artigo foi publicado no I Simpósio Nacional de Estudos Urbanos (Seurb), realizado pela Universidade Estadual do Paraná (Unespar), em 2011, sendo feita a atualização de informações e conceitos em 2021. 
Figura 1. Áreas ocupadas em Ourinhos durante a década de 1930.

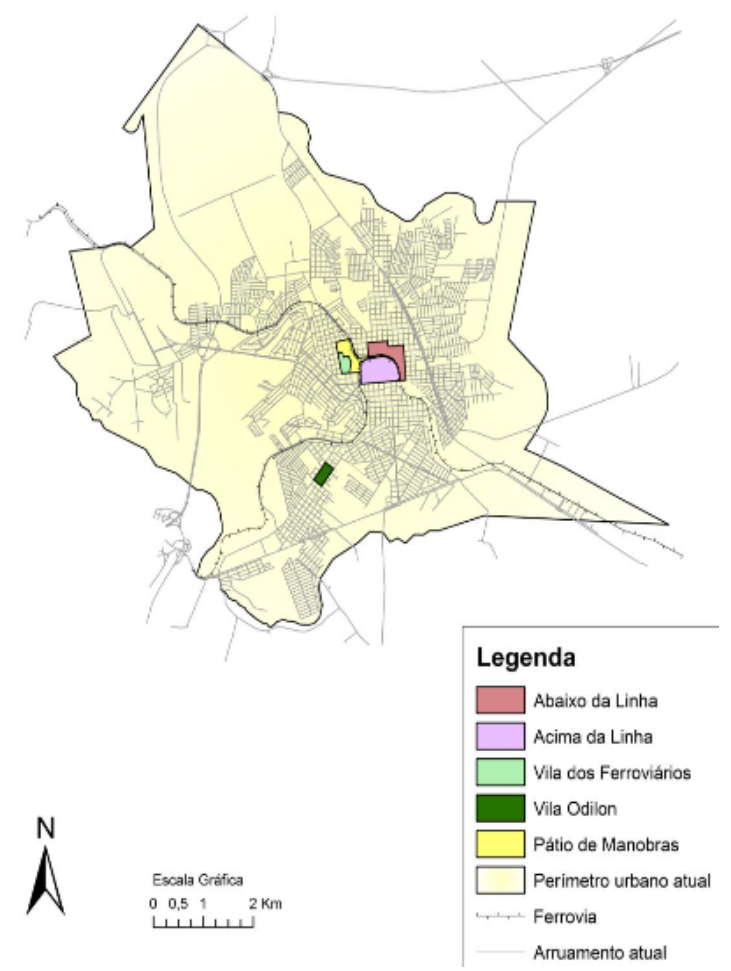

O desenvolvimento da Vila Odilon se deu também por meio da inauguração, em 1929, do trecho entre Ourinhos e Cambará da ferrovia São Paulo-Paraná. A ferrovia era localizada próxima à Vila Odilon e servia para o escoamento da produção das olarias, pois, conforme Massei (2001), a produção de telhas e tijolos tinha como principal destino o norte paranaense. A produção atendia a ação da Companhia Melhoramentos Norte do Paraná (GMNP), sendo criadas cidades como Londrina (1934), Rolândia (1943), Cambé (1947), Arapongas (1947), entre outras, com a utilização dos produtos das olarias de Ourinhos (MONBEIG, 2007).

\section{As Olarias e a Vila OdILON}

A hidrografia do município conta com inúmeros cursos d'água, interessando a este trabalho o rio Paranapanema, que separa Ourinhos e Jacarezinho (PR). Desde o início da ocupação do município tem ocorrido a utilização econômica do rio, por meio da extração de argila, matéria-prima para as olarias. Com isso, desenvolveram-se diversas olarias, inicialmente na Vila Odilon e posteriormente em áreas adjacentes, dando origem aos bairros Vila Musa, Vila Adélia e Vila São Francisco, localizados também na direção do rio Paranapanema. A proximidade das olarias em relação à matéria-prima era fundamental, em vista dos restritos meios de transporte para o escoamento da produção.

A Vila Odilon já existia antes de 1930 e, conforme Massei (2001, p. 39), "o bairro foi crescendo lentamente, nos anos 20 e 30 era praticamente zona rural. Os primeiros moradores foram construindo casas em função de suas atividades". Contudo, antes mesmo que pudesse ser considerado um bairro rural, algumas famílias originárias de Barra Bonita (SP), tais como as de João da Silva Nogueira, João Carnevalle, José Fantinatti, Manoel de Melo etc., iniciaram o aproveitamento da argila do rio Paranapanema.

Entre as décadas de 1930 e 1940, a Vila Odilon estava em processo de formação com a construção das olarias atraídas para produzir nessa região. Segundo o entrevistado, senhor Amílcar, os trabalhadores das olarias eram em sua maioria de origem rural, principalmente da fazenda Água do Jacu, nas adjacências da Vila Odilon, cujas área rural (fazenda) e urbana (Vila Odilon) "se confundiam", havendo dependência de uma em relação à outra. A princípio, conforme o entrevistado, o senhor Amílcar, havia inúmeras famílias que se dedicavam ao cultivo do café, mas devido ao grande isolamento do bairro - não havia vias de acesso, apenas um caminho de terra que dava acesso à rua Paraná - e à grande distância - cerca de cinco quilômetros da área urbanizada da época - ele ganhou "vida própria" e características peculiares.

De acordo com o senhor Amílcar, entre as décadas de 1940 e 1950 a Vila Odilon ainda era um foco de ocupação urbana isolada; da localização da cerâmica Fantinatti adiante não havia mais nada à época, existindo apenas fazendas como a Chumbeadinha. Portanto, o bairro ainda não era conectado com a cidade de Ourinhos em si, conforme se observa na figura 2 :

Figura 2. Vista parcial de Ourinhos, com a Vila Odilon localizada na parte superior da figura.

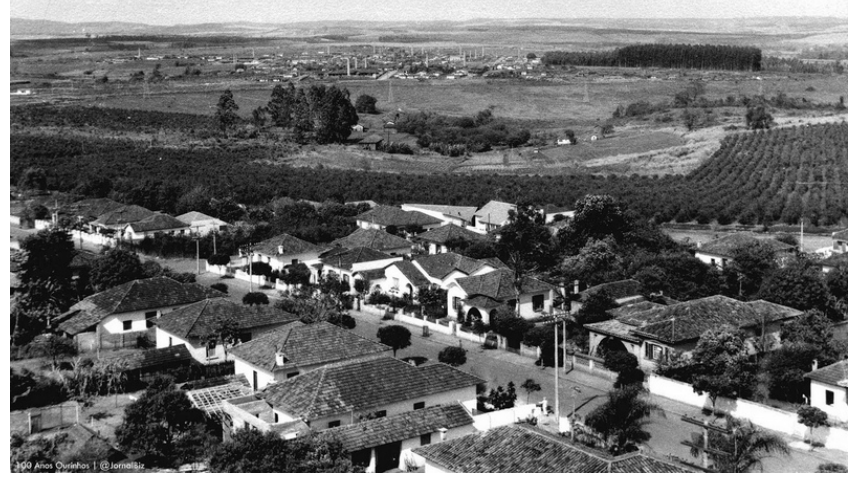

Fonte: Prefeitura Municipal de Ourinhos (194-?). 
No local onde atualmente está a garagem da empresa de ônibus Manoel Rodrigues havia um campo de futebol, e o formato da praça da paróquia Santo Antônio era diferente. No sentido do rio Paranapanema já havia outro núcleo urbano em formação, a Vila Musa, que na década de 1950 não possuía muitas casas, pois as olarias estavam em desenvolvimento nesse bairro.

A Vila Odilon passou a se desenvolver em 1943, quando foi instalada a luz elétrica e o primeiro telefone público. Havia as olarias Bertagnolli, Buratti, Gimenes, Pasqueta, Figueira, Biazoy e Soares, a arrozeira São Geraldo, dos irmãos Zaia, e a indústria Migliari, que produzia máquinas e peças utilizadas pelas olarias de Ourinhos. Tudo isso confirmava o aspecto fabril da Vila Odilon, que se tornou ainda mais relevante por meio da criação da Colchões Castor ${ }^{3}$ em 1962, atualmente uma das maiores indústrias de Ourinhos. $\mathrm{O}$ desenvolvimento do bairro contribuiu para a construção de uma escola, um posto de saúde e uma agência dos Correios (figura 3), além da expansão do comércio local.

Figura 3. Vista parcial da antiga agência dos Correios, localizada na Vila Odilon.

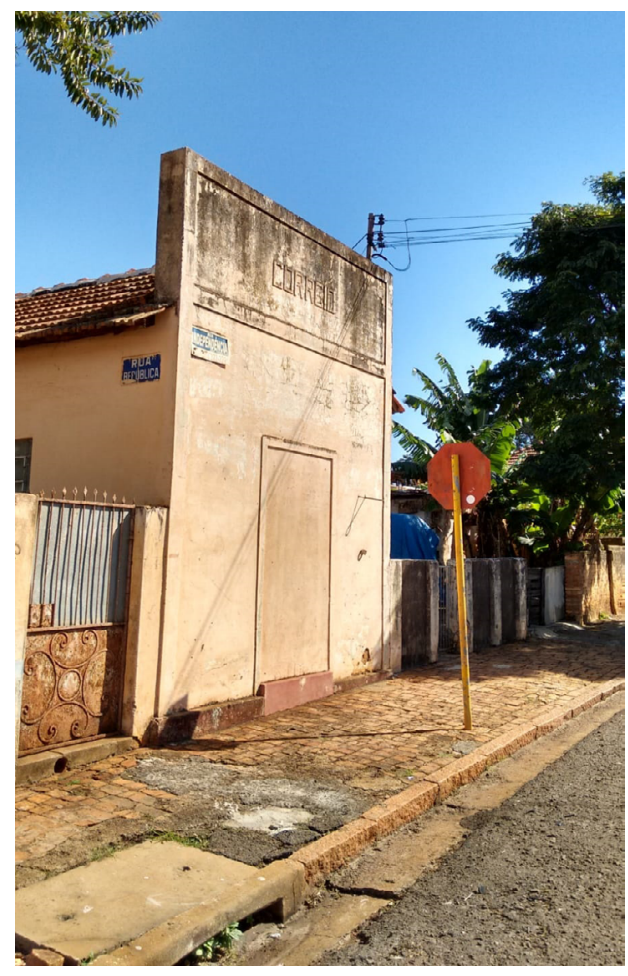

3 A Colchões Castor é uma das maiores empresas de colchões do Brasil. Foi criada na Vila Musa, em 1962, permanecendo no local até 1983, quando se mudou para o Distrito Industrial I.
De acordo com Massei (2001), os proprietários das olarias moravam no local, havendo, assim, uma classe proprietária dentro do bairro industrial. Alguns operários viviam em casas nos terrenos das olarias, casas contíguas às empresas, o que mantinha os empregados próximos ao seu trabalho para que pudessem ser convocados em qualquer eventualidade. Essa situação perdurou por muito tempo, visto que o mercado de trabalho das olarias era no próprio bairro. Observamse na figura 4 casas ainda presentes em áreas contíguas às olarias.

Figura 4. Residências no pátio de olarias.

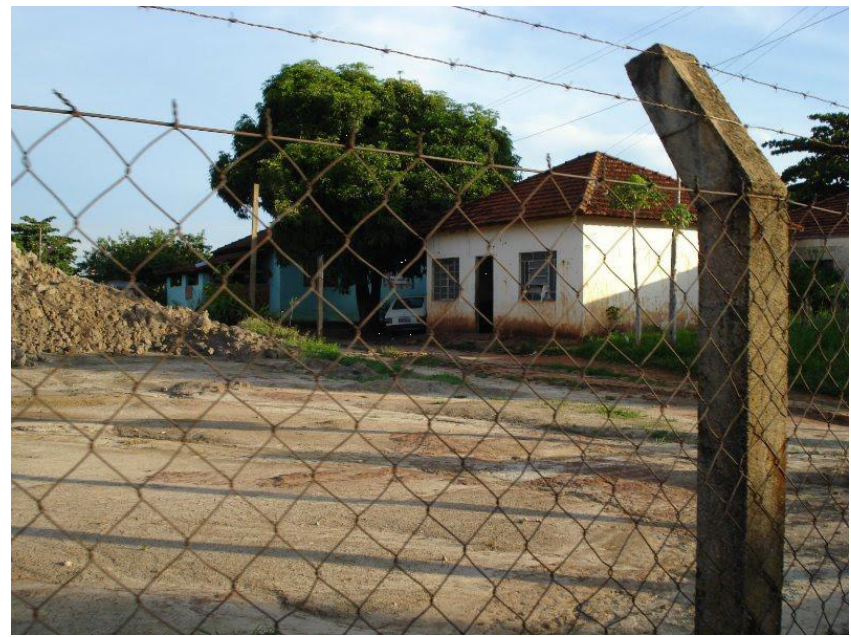

Bonduki (1998, p. 41) ressalta que, "baseada na casa unifamiliar, a Vila operária era o modelo de habitação econômica e higiênica, o ideal a ser atingido". As vilas operárias tinham o objetivo de difundir os padrões de comportamento adequados, na óptica capitalista do desempenho do trabalho livre. O entrevistado, senhor Amílcar, relatou que, realmente, o bairro, apesar da má fama de violento e pobre, prezava pelos bons costumes. Por exemplo, a praça Ítalo Ferrari, da paróquia Santo Antônio, era frequentada por famílias inteiras que nas horas vagas do trabalho nas olarias procuravam se divertir, mas "com modos".

A Vila Odilon contava com vários equipamentos coletivos, como escolas, igrejas, clubes e pequenos comércios. A localização das olarias era estratégica próxima ao norte do Paraná - devido à facilidade de transporte, como a ferrovia, a rodovia Mello Peixoto, que se liga ao estado do Paraná, e a rodovia Raposo Tavares. A atividade fabril era apoiada pelo Estado, que, a partir da década de 1950, iniciou melhorias na infraestrutura no bairro, justamente quando teve início o crescimento do setor. Apesar disso, as carências eram 
evidentes e reconhecidas pelo poder público, posto que o diagnóstico do município feito pelo Grupo de Planejamento Integrado (GPI/Planurb) ${ }^{4}$ descreveu como era a Vila Odilon e as adjacências na década de 1960.

Além do loteamento de mesmo nome, inclui Vila São Francisco, Vila São José, Vila Santa Maria, Vila Musa, Vila Adélia e Vila Maria. Formou-se em torno de uma série de olarias e da antiga estrada para o Paraná. “_” é um bairro "operário"; e nele não há um núcleo comercial. Os equipamentos mais deficientes: esgotos, pavimentação e de recreação para adultos. Há um parque infantil, uma escola primária e um edifício para culto. As edificações são em parte em madeira, parte em alvenaria. Cerca de 50\% das ruas têm energia elétrica; não há rede de esgotos sanitários; cerca de $30 \%$ das ruas têm água canalizada, menos de $15 \%$ tem pavimentação; cerca de $20 \%$ têm rede de telefone, não há arborização e cerca de $20 \%$ das ruas têm serviço de coleta de lixo. (MASSEI, 2001, p. 40)

Assim, a Vila Odilon permanecia em situação de segregação socioespacial, pois, além da distância geográfica da área urbanizada, havia pouca infraestrutura e seus moradores eram discriminados (DIAS, 2013). Massei (2001, p. 147) salienta que a população ourinhense marginalizava o bairro: "Esse sentimento de posse é reflexo, de alguma maneira, do distanciamento que havia entre os habitantes do centro de Ourinhos e de outros bairros. Eles pareciam desconhecer ou ignorar a existência dos trabalhadores oleiros".

De acordo com o entrevistado, o senhor Amílcar, na década de 1960 o bairro ainda não possuía pavimentação asfáltica, mas, em contrapartida, havia lixeiros que recolhiam o lixo com uma carroça e a prefeitura jogava água nas ruas quando o tempo estava muito seco. Para o entrevistado, a assistência da prefeitura ao bairro sempre foi precária, melhorando somente quando da gestão ${ }^{5}$ de Domingos Camerlingo Caló e de Aldo Matachana Thomé.

4 Estudo realizado pela Prefeitura Municipal de Ourinhos na década de 1960.

5 Aldo Matachana Thomé foi prefeito entre 1977 e 1983 e Domingos Camerlingo Caló entre 1952 e 1955.

\section{A MECANIZAÇÃO DAS OLARIAS E AS TRANSFORMAÇÕES SOCIOESPACIAIS DA VILA ODILON}

Até o auge da atividade oleira, na década de 1980, o setor ainda não havia passado por um processo de mecanização de fato, o que se deu após a década de 1990, com a transformação de algumas olarias em cerâmicas e modificações no relacionamento entre patrões e empregados, deixando as relações paternalistas de lado, além do uso de maior mecanização no processo produtivo. Em 1990 havia 87 cerâmicas, entre as quais 40 eram mecanizadas.

As mudanças que desencadearam a modernização do setor foram uma resposta ao declínio da atividade, no final da década de 1980, cujo principal motivo foi a dificuldade de obtenção da matéria-prima (argila) e a concorrência com outros materiais, como telhas de amianto e de alumínio, além de zinco e cimento.

A inundação provocada pelas novas usinas hidrelétricas teria sido responsável pela escassez da matériaprima, já que o local de extração se tornou distante das empresas. Somente as empresas que possuíam suas próprias áreas continuaram a extração sem problemas. Atualmente, conforme o entrevistado, senhor Sidney, devido aos entraves ambientais e à escassez da matériaprima nas proximidades de Ourinhos, as olarias têm adquirido argila em municípios localizados às margens do rio Tibagi e do rio Laranjinha, no Paraná.

De acordo com Massei (2001), apenas as empresas mais fortes e bem administradas, principalmente aquelas em que a segunda geração de proprietários deu melhor continuidade, é que progrediram e até mesmo ampliaram a produção.

O processo de valorização imobiliária, conforme o senhor Eitor, ocorreu principalmente após as ações relativas ao Programa de Aceleração do Crescimento (PAC) e os investimentos imobiliários na construção de pequenos condomínios e quitinetes, substituindo antigas residências, muitas delas deterioradas. Apontase ainda o Programa Minha Casa, Minha Vida, que contribuiu para a criação de novos bairros, resultando na expansão urbana, principalmente na região leste da cidade, bem como a inauguração dos Conjuntos Habitacionais Ourinhos G e H, o que acabou valorizando bairros antigos da cidade, tais como a Vila Odilon e a Vila Margarida (antiga Vila dos Ferroviários), que se tornaram bairros pericentrais. 
Após meados da década de 1970, a Vila Odilon se tornou totalmente integrada à cidade, conectando-se aos bairros Vila São José e Jardim Matilde, loteamentos iniciados na década de 1960, preenchendo o vazio urbano que ainda existia. Também se destaca a pavimentação e as melhorias efetuadas na avenida Domingos Camerlingo Caló, principal ligação entre o centro e a região Sul, perpassando os bairros Jardim Matilde, Vila Odilon, Vila São Francisco, Vila Adélia e Vila Musa, e findando na rodovia Melo Peixoto, um dos acessos ao estado do Paraná.

A avenida Domingos Camerlingo Caló tem passado por um processo de reestruturação por meio da substituição de antigas residências e vazios urbanos por estabelecimentos de comércio e serviços, conforme se nota na figura 5. A exemplo disso, foram inaugurados, na última década, três supermercados (rede Avenida, Maitan e São Judas Tadeu), um posto de gasolina, uma loja de material de construção, academias, restaurantes, cafés, lojas, serviços automobilísticos, escritórios de advocacia, bares, salões de beleza, consultório dentário, sorveteria (rede Adorei), igrejas, loja de tintas etc.

Figura 5. Vista parcial do supermercado Avenida; ao fundo, olarias.

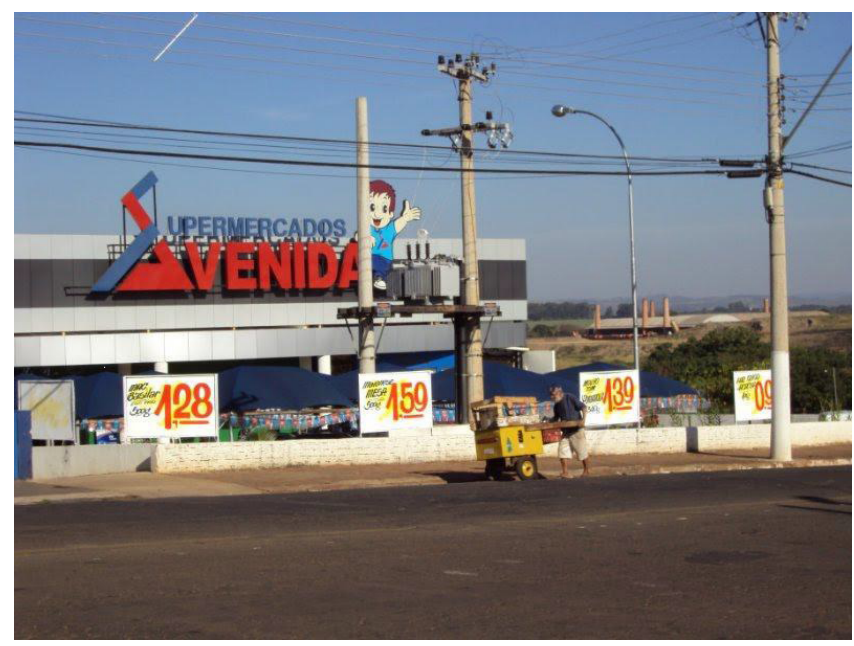

\section{A Vila Odilon e as olarias atualmente}

Bastante veiculados pela imprensa local e por autores da história de Ourinhos, os problemas com a extração de argila e a falta de modernização do setor teriam levado à quebra da maioria das olarias de Ourinhos, deixando de ser uma atividade econômica relevante. Entretanto, o que se observou, em visita de campo em 2021, foi uma situação distinta disso: 1) uma forte presença das olarias, em atividade ou não, mantendo a característica da Vila Odilon, conhecida como o "bairro das olarias"; 2) a atividade econômica ainda tem relevância e emprega moradores, principalmente da região Sul da cidade; 3) apesar da integração do bairro com o restante da cidade, ainda se mantém parte de suas características que, no passado, denotavam que a Vila Odilon era um "lugar à parte", com "vida própria", conforme as palavras do senhor Amílcar.

As olarias ainda estão presentes em toda a Vila Odilon, Vila Musa, Vila Adélia, Vila São Francisco e adjacências, incluindo a rodovia Melo Peixoto e os arredores da ferrovia São Paulo-Paraná, atualmente Jardim Esplendor. Algumas olarias não se encontram em atividade, denotando total abandono e degradação, a exemplo das olarias localizadas na rua Padre Rui Cândido da Silva, na Vila Odilon (figura 6). Porém, a parte dessa olaria que se encontra mais preservada - onde funcionava a administração - apresentou diferentes usos, de forma que, em 2011, estava alugada para uma igreja evangélica e atualmente é ocupada por uma serralheria.

Figura 6. Ruínas de olarias localizadas na rua Padre Rui Cândido da Silva.

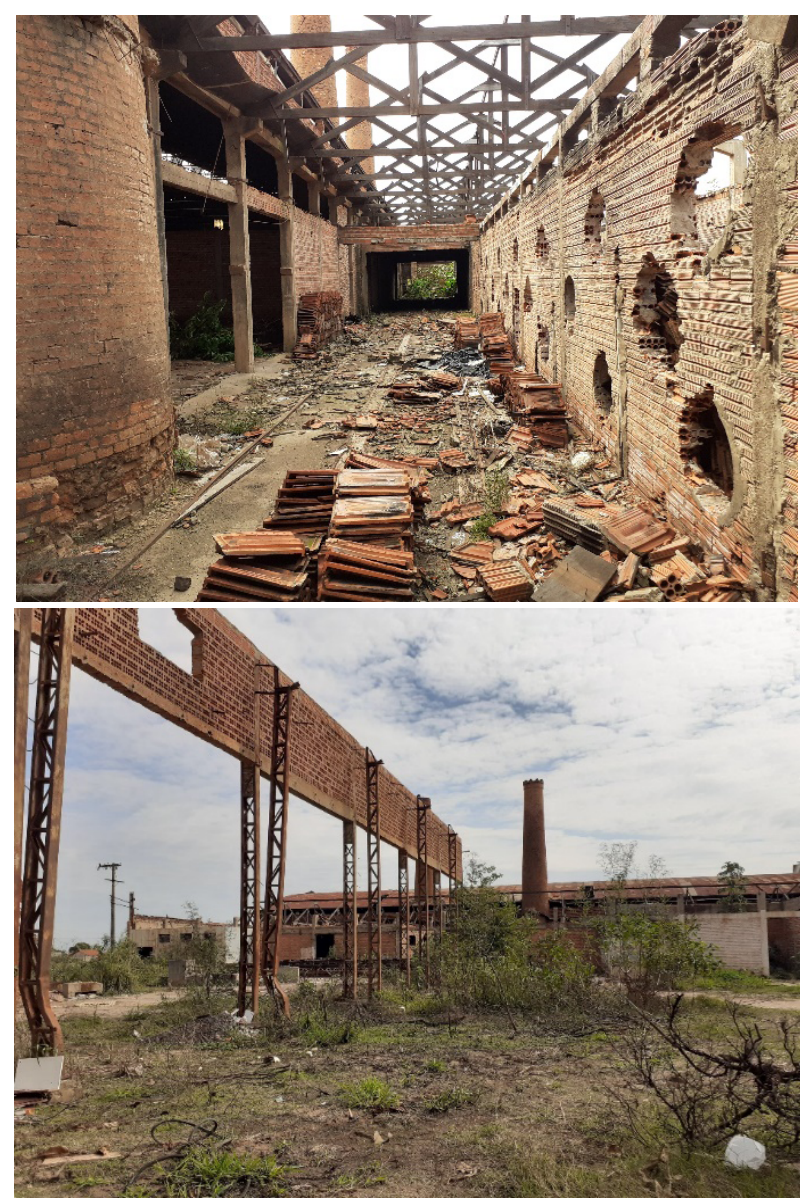


O citado processo de modernização das olarias, a partir do qual algumas foram transformadas em cerâmicas, não foi observado em todos os casos, como no caso da olaria Estrela, situada na rua Fernando Sanches, Vila São Francisco. Na figura 7 se destacam dois aspectos: 1) as residências contíguas às olarias ainda são comuns; 2) as olarias continuam presentes em toda a região e nos arredores da Vila Odilon, sendo normalmente compostas por instalações bastante simples.

Figura 7. Vista parcial das instalações da olaria Estrela.

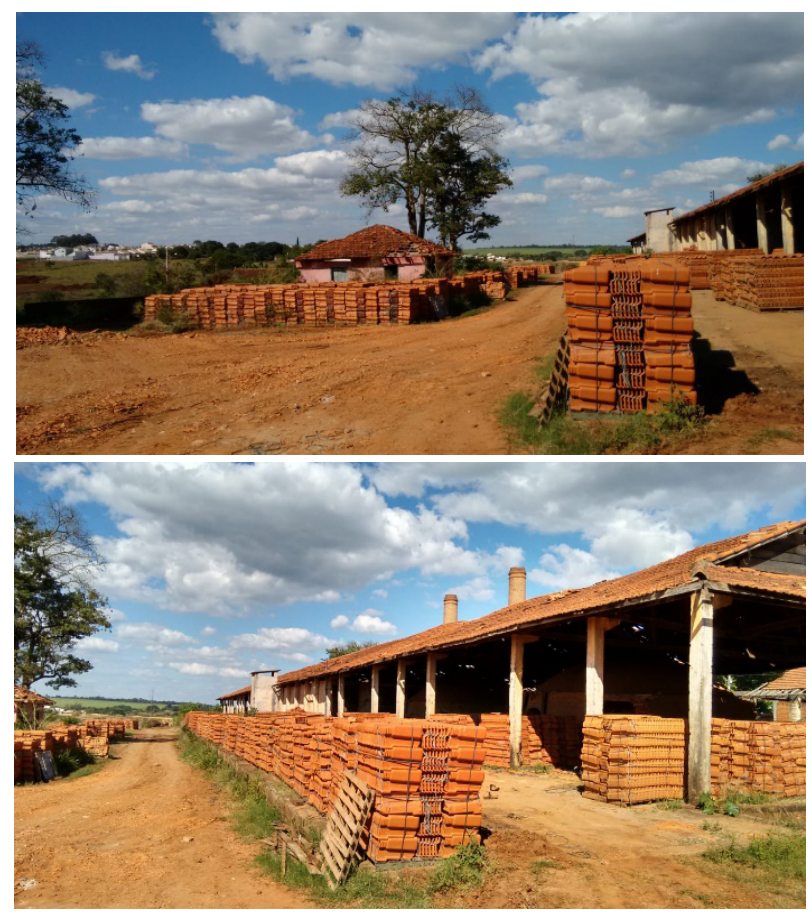

Conforme o senhor Sidney, a maioria das olarias são pequenas e produzem majoritariamente para a região de Ourinhos, empregando entre 10 e 20 funcionários. O trabalhador considera que o crescimento do setor da construção civil tem beneficiado as olarias, pois a demanda por telhas e tijolos aumentou, principalmente nos últimos anos. Na olaria Ourily, de pequeno porte, o trabalhador estima que são produzidas por semana cerca de 90 mil unidades, entre telhas e tijolos. Conforme se observa na figura 8, a Ourily é composta por um escritório, uma área coberta para armazenagem de matéria-prima/produtos e quatro fornos, que demandam grande quantidade de lenha.
Figura 8. Vista parcial da olaria Ourily, localizada na Vila Adélia.
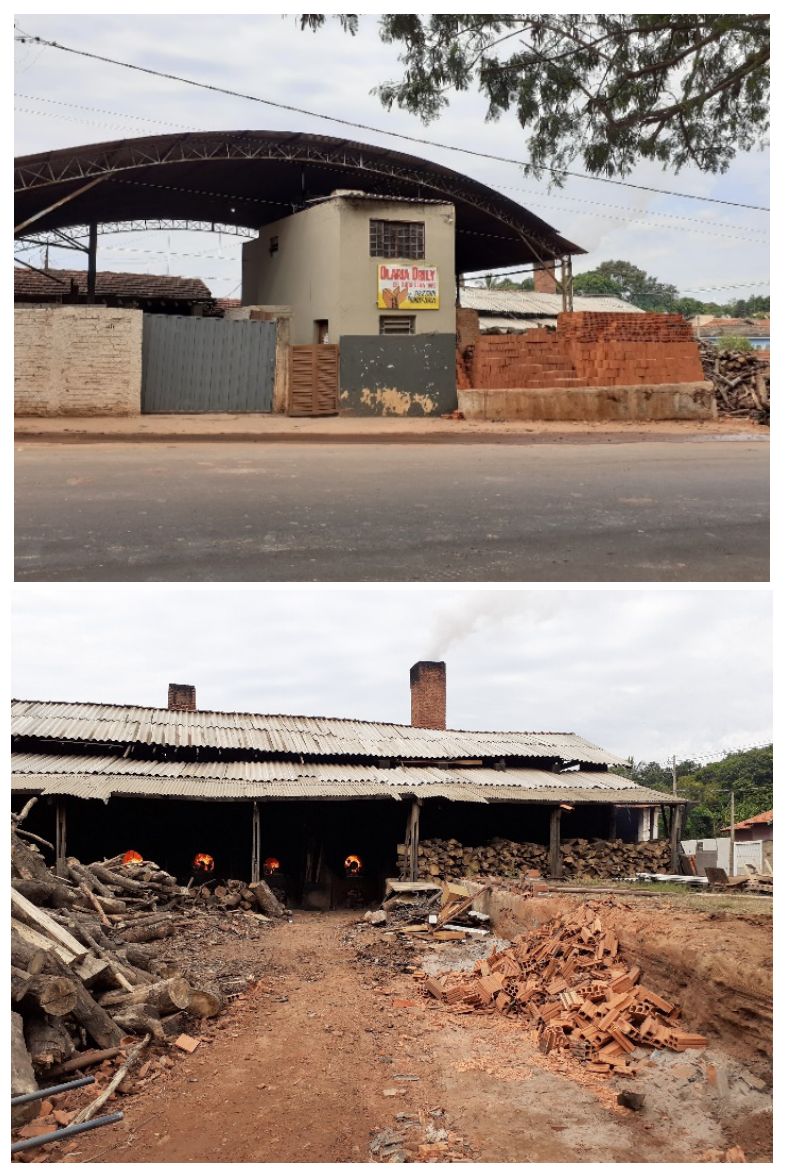

Algumas olarias se dedicam também à fabricação de filtros de barro e itens de decoração e jardinagem. As olarias consideradas mecanizadas e de maior porte são a Teto Forte, localizada na Vila Musa, a Santa Bárbara e a J. Albano, ambas localizadas na rodovia Melo Peixoto, no bairro Parque Pacheco Chaves.

A rua Padre Rui Cândido da Silva é considerada a primeira rua criada na Vila Odilon, anteriormente denominada de "rua Paranapanema ou Estrada do Paranapanema", por dar acesso ao rio homônimo e apresentar importância para as olarias, pois era o caminho utilizado para o acesso à matéria-prima (DIAS, 2013).

A praça Ítalo Ferrari, especificamente, localizada na rua Padre Rui Cândido da Silva foi apontada pelo senhor Amílcar como o centro da Vila Odilon no passado, principal ponto de encontro dos moradores. Atualmente, notou-se que, apesar da criação e expansão recente dos comércios e serviços na avenida Domingos Camerlingo Caló, a praça ainda denota centralidade no bairro, pois 
concentra estabelecimentos tradicionais como o bar Joia, fundado na década de 1940, além de um armarinho sem nome, fundado na mesma década.

Verificou-se, na praça Ítalo Ferrari e proximidades, estabelecimentos comerciais e prestadores de serviços, tais como padaria, loja de roupas, pet shop, restaurante, brechó, loja de móveis usados, autopeças, bares, farmácia, salões de beleza, oficinas mecânicas, lotérica, costureira, garagem de empresa de ônibus, entre outros. Apesar disso, há estabelecimentos abandonados, terrenos que anteriormente possuíam uma residência ou estabelecimento e que passaram por demolição. Nas ruas adjacentes, há supermercados, postos de saúde e escolas. Observa-se na figura 9 a rua Padre Rui Cândido da Silva.

Figura 9. Vista parcial da rua Padre Rui Cândido da Silva.

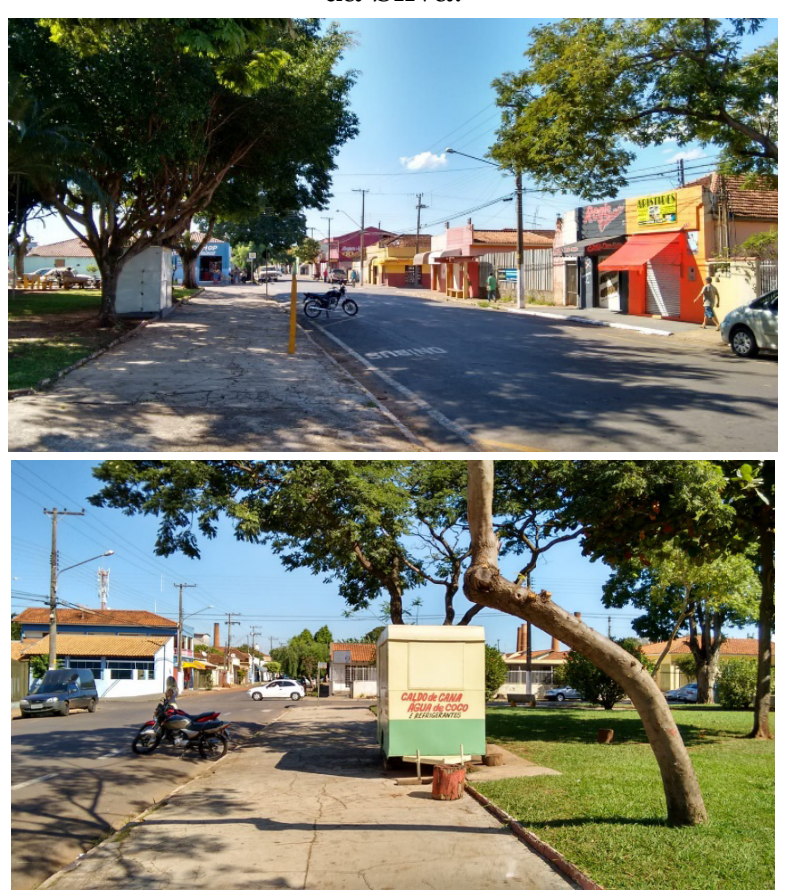

Na rua Imprensa, nos arredores da Praça Ítalo Ferrari, encontra-se em funcionamento a cerâmica São
Pedro (figura 10), apontada pelo trabalhador Sidney como uma das mais dinâmicas da cidade.

Figura 10. Vista parcial da cerâmica São Pedro.
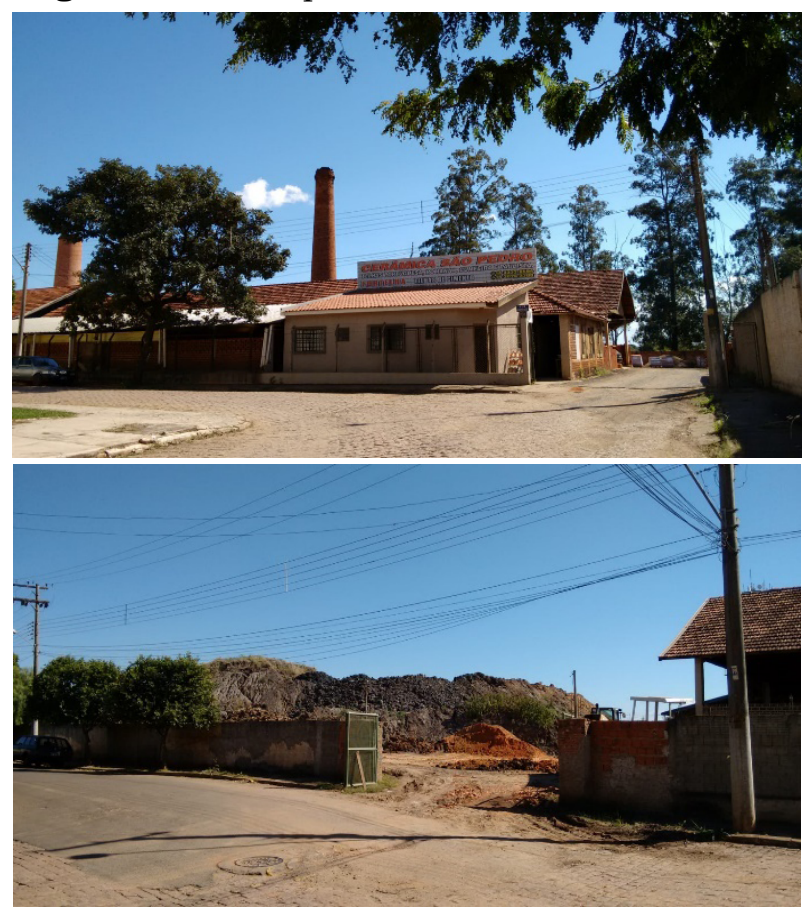

Porém, são diversos os elementos presentes na praça Ítalo Ferrari e arredores que contribuem para que a Vila Odilon ainda se mantenha como um "lugar à parte" com "vida própria". A tradicional quermesse da Vila Odilon, promovida no mês de junho pela paróquia Santo Antônio, localizada na praça Ítalo Ferrari, atrai, conforme os moradores entrevistados, participantes de toda a cidade de Ourinhos, sendo realizada há mais de 60 anos, que teriam sido ininterruptos caso não houvesse ocorrido a pandemia de coronavírus. Ligada à igreja, há uma livraria voltada para produtos religiosos e o salão paroquial, onde frequentemente realizam-se festas de casamento, entre outras festividades. A figura 11 apresenta a paróquia Santo Antônio. 
Figura 11. Vista parcial da paróquia Santo Antônio.

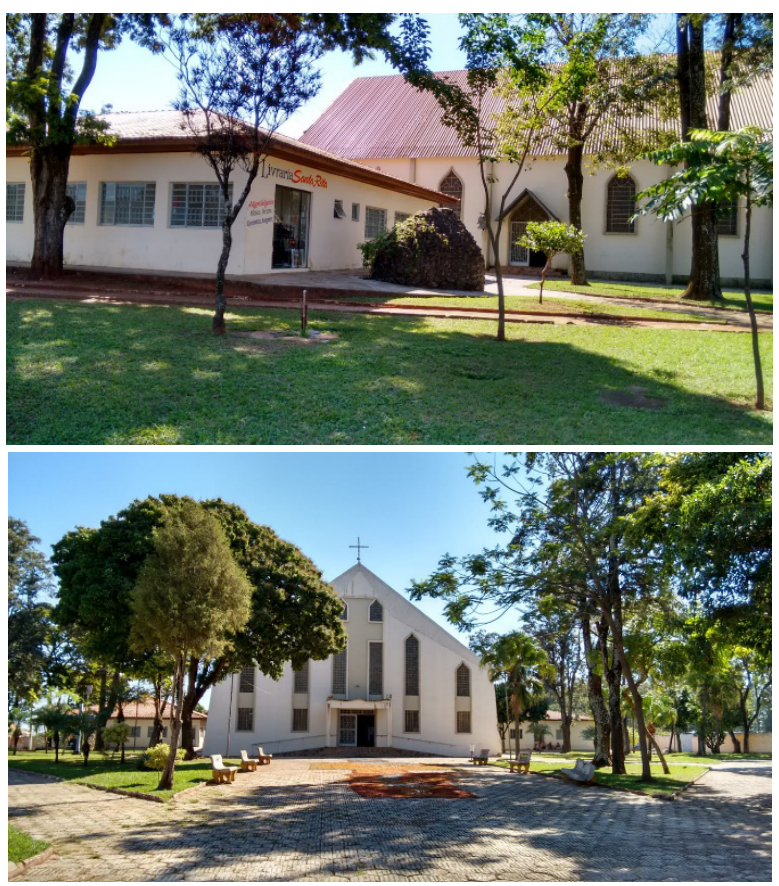

A praça continua sendo utilizada como local de convivência pelos moradores locais, conforme se observa na figura 12. Além disso, deve-se também citar o Centro Cívico da Vila Odilon (CGVO), localizado na rua Liberdade, como um local de convivência dos moradores do bairro. No local há quadras coberta e não coberta, além de campo de futebol, palco dos campeonatos de futebol amadores, que contam inclusive com times que representam "a região das olarias", a exemplo do Teto Forte Esporte Clube, ligado à cerâmica Teto Forte.

Figura 12. Vista parcial da praça Ítalo Ferrari.

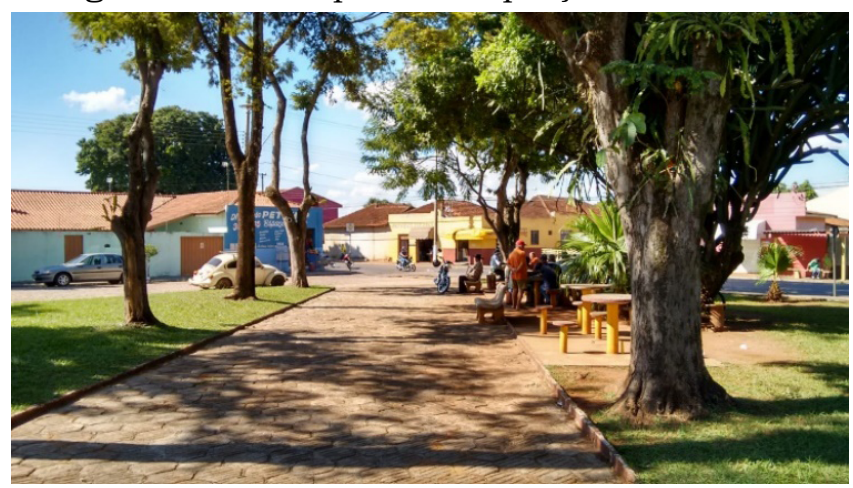

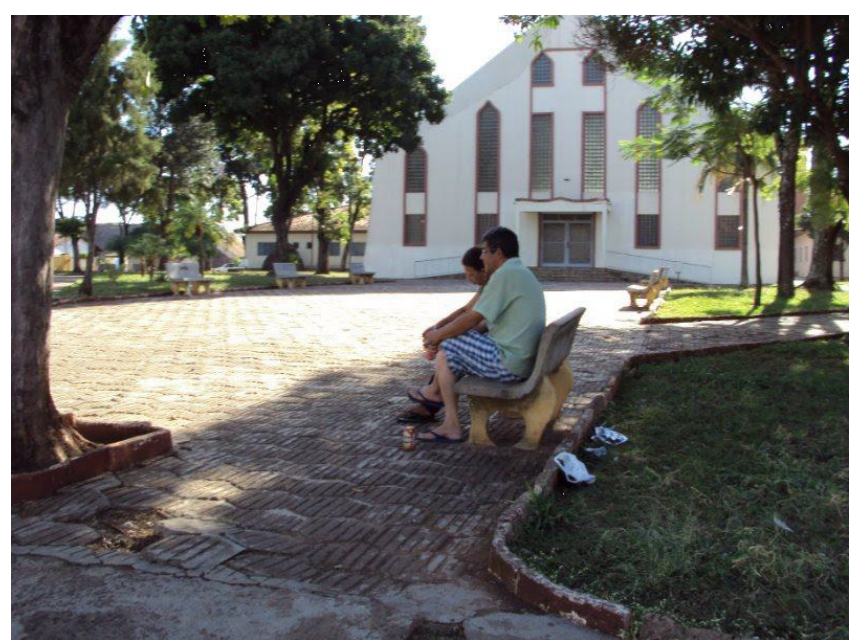

Segundo Santos (2004, p. 173), "o modo de produção que, por intermédio de suas determinações (em mesmo lugar pode-se ter, ao mesmo tempo, determinações diferentes) cria formas espaciais fixas pode desaparecer". Isso se verifica em Ourinhos, pois a economia deixou de ser há muito tempo baseada na indústria oleira e passou a se pautar no agronegócio da cana-de-açúcar e no setor terciário, embora não se possa excluir o papel do setor oleiro.

Verificou-se na Vila Odilon a forte presença das olarias - em funcionamento ou desativadas - e um comércio de bairro com inúmeros estabelecimentos comerciais tradicionais, juntamente com a igreja Santo Antônio, que dão ao bairro a aparência de outra cidade dentro de Ourinhos. Conforme se observa na figura 13, trata-se, de fato, do bairro das olarias, com suas chaminés que já não funcionam como nos tempos áureos do setor, mas que não deixam esquecer a história local.

Figura 13. Vista da Vila Odilon e adjacências, 2018.

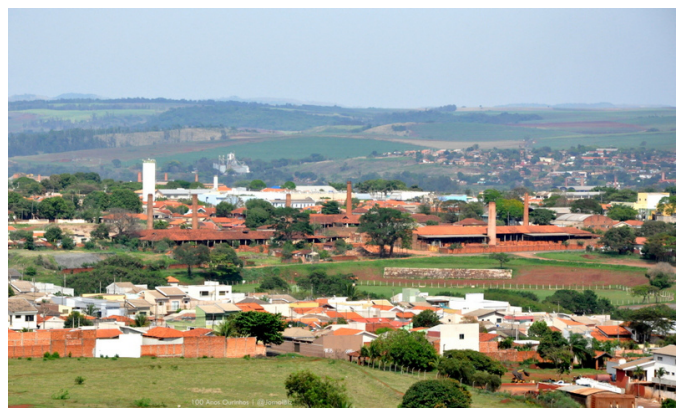

Fonte: Prefeitura Municipal de Ourinhos (2018). 


\section{CONSIDERAÇÕES FINAIS}

Considera-se que não só a Vila Odilon, mas também a cidade de Ourinhos, tiveram uma expansão urbana bastante lenta entre a fundação e a década de 1950 , sendo um período em que o Brasil, de forma geral, ainda era predominantemente rural. Nesse período ocorreu a criação das olarias e a expansão da produção de telhas e tijolos, atendendo a demanda gerada pela criação de cidades no norte paranaense. Porém, o bairro era marcadamente rural, pois a população ainda mantinha hábitos rurais - como os cultivos de subsistência -, a distância para a área urbanizada era de cerca de três quilômetros e não havia vias de acesso que ligassem a cidade de Ourinhos à Vila Odilon.

A gênese da Vila Odilon se atrela à criação das olarias, que se beneficiavam da proximidade da matéria-prima, a argila, oriunda do rio Paranapanema. A criação de mais olarias deu origem à Vila Musa na década de 1950 e, posteriormente, aos demais loteamentos locais. Porém, a Vila Odilon continuava mantendo sua centralidade, dada a relevante atividade comercial e de serviços desenvolvida principalmente na rua Padre Rui Cândido da Silva.

As transformações começaram a se tornar mais evidentes após a década de 1960, devido às ações do poder público local quanto à dotação de infraestrutura e serviços públicos e em razão da importância econômica que o setor oleiro estava adquirindo. A partir disso, a Vila Odilon foi urbanizada e integrada à cidade de Ourinhos, visto que os vazios urbanos entre ambas foram paulatinamente substituídos pela criação de bairros como Jardim Matilde, Vila São José e, mais recentemente, a Cohab Padre Eduardo Murante.

Após a década de 1990 ocorreram transformações nos processos produtivos empregados pelas olarias, com a modernização de algumas, que se tornaram cerâmicas. As dificuldades de obtenção da matéria-prima, associadas à modernização do setor e à concorrência com novos materiais que passaram a substituir as telhas, contribuíram para a falência de muitas olarias. Após a década de 2000 ocorreu um processo de valorização imobiliária e expansão dos investimentos em comércios e serviços, tornando o eixo representado pela avenida Domingos Camerlingo Caló bastante importante no contexto municipal.

A Vila Odilon é atualmente um bairro que tem se valorizado em razão da incorporação do capital imobiliário, manifesto na criação recente de condomínios de quitinetes e na substituição de antigas residências degradadas por novas ou por estabelecimentos comerciais e prestadores de serviços, vinculados inclusive às redes varejistas. Apesar disso, foi possível perceber, nas entrevistas realizadas e na observação em campo, que os moradores, além da identificação forte com o bairro, se "apoderaram" desse espaço geográfico. Esse espaço tem características diferentes de qualquer outra parte da cidade devido à aparência nostálgica de suas ruas principais e, principalmente, pela forte presença das olarias, que não deixam esquecer que a Vila Odilon ainda é o "bairro das olarias".

\section{REFERÊNCIAS}

BONDUKI, N. Origens da habitação social no Brasil: arquitetura moderna, lei do inquilinato e difusão da casa própria. São Paulo: Estação Liberdade, 1998.

DEL RIOS, J. Ourinhos: memórias de uma cidade paulista. São Paulo: Imesp, 1992.

DIAS, F. F. A gênese da cidade acima e abaixo da linha. Geoingá, Maringá, v. 6, n. 1, p. 46-61, 2014.

DIAS, F. F. Segregação residencial na cidade de Ourinhos-SP. 2013. Dissertação (Mestrado em Geografia) - Universidade Estadual de Maringá, Maringá, 2013.

MASSEI, R. C. As inovações tecnológicas e o caso dos oleiros: a mecanização das olarias em Ourinhos 19501990. 2011. Dissertação (Mestrado em História) - Pontificia Universidade Católica de São Paulo, São Paulo, 2001.

MONBEIG, P. A zona pioneira do norte do Paraná. In: CARVALHO, M. S.; FRESCA, T. M. (org.). Geografia e norte do Paraná: um resgate histórico. Londrina: Humanidades, 2007. v. 2, p. 1-18.

MOnBeig, P. Pioneiros e fazendeiros de São Paulo. São Paulo: Hucitec: Polis, 1984.

OURINHOS. Plano diretor: 2018. Ourinhos: Prefeitura Municipal, 2018. Disponível em: https://bit.ly/3IYbOV3. Acesso em: 22 mar. 2020.

SANTOS, M. Por uma geografia nova. São Paulo: Hucitec: Edusp, 2004. 